\title{
Impact of BMI on exacerbation and medical care expenses in subjects with mild to moderate airflow obstruction
}

This article was published in the following Dove Press journal: International Journal of COPD

\author{
Yong Suk Jo,' Yee Hyung \\ Kim, ${ }^{2}$ Jung Yeon Lee, ${ }^{3}$ \\ Kyungjoo Kim, ${ }^{4}$ Ki-Suck \\ Jung, ${ }^{5}$ Kwang $\mathrm{Ha} \mathrm{Yoo,}{ }^{6}$ Chin \\ Kook Rhee ${ }^{4}$
}

'Division of Pulmonary and Critical Care Medicine, Department of Internal Medicine, Kyung Hee University Hospital, Seoul, Republic of Korea; ${ }^{2}$ Division of Pulmonary and Critical Care Medicine, Department of Internal Medicine, Kyung Hee University Hospital at Gangdong, Seoul, Republic of Korea; ${ }^{3}$ Division of Pulmonary and Critical Care Medicine, Department of Internal Medicine, Konkuk University Chungju Hospital, Chungju, Republic of Korea; ${ }^{4}$ Division of Pulmonary, Allergy and Critical Care Medicine, Department of Internal Medicine, College of Medicine, Seoul St Mary's Hospital, The Catholic University of Korea, Seoul, Republic of Korea; ${ }^{5}$ Division of Pulmonary, Allergy and Critical Care Medicine, Department of Internal Medicine, Hallym University Sacred Heart Hospital, Hallym University College of Medicine, Anyang, Republic of Korea; ${ }^{6}$ Department of Internal Medicine, Konkuk University School of Medicine, Seoul, Republic of Korea

Correspondence: Chin Kook Rhee Division of Pulmonary, Allergy and Critical Care Medicine, Department of Internal Medicine, College of Medicine, Seoul St Mary's Hospital, The Catholic University of Korea, 222 Banpo-daero, Seocho-gu, Seoul 0659I, Republic of Korea

Tel +82 222586067

Fax +82 25993589

Email chinkook77@gmail.com
Background and objective: The rate of obesity is increasing in Asia, but the clinical impact of body mass index (BMI) on the outcome of chronic obstructive pulmonary disease (COPD) remains unknown. We aimed to assess this impact while focusing on the risk of exacerbation, health-care utilization, and medical costs.

Methods: We examined 43,864 subjects registered in the Korean National Health and Nutrition Examination Survey (KNHANES) database from 2007 to 2012, and linked the data of COPD patients who had mild to moderate airflow obstruction $(n=1,320)$ to National Health Insurance (NHI) data. COPD was confirmed by spirometry. BMI was used to stratify patients into four categories: underweight $\left(\mathrm{BMI}<18.5 \mathrm{~kg} / \mathrm{m}^{2}\right)$, normal range $\left(18.5-22.9 \mathrm{~kg} / \mathrm{m}^{2}\right)$, overweight $\left(23-24.9 \mathrm{~kg} / \mathrm{m}^{2}\right)$, and obese $\left(\geq 25 \mathrm{~kg} / \mathrm{m}^{2}\right)$.

Results: Of the 1,320 patients with COPD with mild to moderate airflow obstruction, $27.8 \%$ had a BMI $\geq 25 \mathrm{~kg} / \mathrm{m}^{2}$. Compared with normal-weight patients, obese patients tended to experience fewer exacerbations (incidence rate ratio [IRR] 0.88; 95\% CI 0.77-0.99; $P=0.04$ ), although this association was not significant in a multivariable analysis. COPD-related health-care utilization and medical expenses were higher among underweight patients than the other groups. After adjustment, the risk of COPD-related hospitalization was highest among underweight and higher among overweight patients vs normal-weight patients (adjusted IRRs: 7.12, 1.00, 1.26, and 1.02 for underweight, normal, overweight, and obese groups, respectively; $P=0.01$ ).

Conclusion: Decreased weight tends to negatively influence prognosis of COPD with mild to moderate airflow obstruction, whereas higher BMI was not significantly related to worse outcomes.

Keywords: COPD, obesity, exacerbation, health-care utilization, medical expenses

\section{Introduction}

Chronic obstructive pulmonary disease (COPD) is a major cause of morbidity and mortality worldwide and has an increasing prevalence. ${ }^{1}$ COPD does not merely comprise progressive lung disease, but is complicated by associations with several comorbid conditions that contribute to a poor health status and increases in health-care utilization and expenses, hospitalization, and mortality. According to a previous epidemiologic report, more than $50 \%$ of patients with COPD have at least one comorbidity. ${ }^{2}$ Obesity, a known comorbidity of COPD, may contribute to a patient's respiratory symptoms and reduced exercise capacity. ${ }^{3-5}$ Paradoxically, despite the propensity of obesity to increase the prevalence rates of various diseases and cause unfavorable outcomes in the general population, large cohort studies have demonstrated an association of obesity with reduced mortality among patients with COPD. ${ }^{6,7}$ In those studies, mortality was 
highest among patients with a low body mass index (BMI), whereas overweight - but not extremely obese - patients exhibited improved survival. This finding suggests a survival benefit associated with increased BMI among overweight and mildly obese patients. However, previous studies of obesity among patients with COPD included symptomatic patients who received treatment and were followed regularly.

The low prevalence of obesity in Asian populations relative to Western populations has led to few reports of the impact of BMI on COPD. However, obesity is increasing among Asians in response to increasingly Westernized diets. ${ }^{8,9}$

It is extremely difficult to enroll patients with mild, asymptomatic COPD who rarely visit hospital, in clinical trials or cohort studies, and this results in lack of data on the clinical features of those patients. However, we can evaluate these patients through our unique national insurance system. In the present study, we aimed to identify the clinical impact of BMIs on the outcome of patients with mild, asymptomatic COPD with mild to moderate airflow obstruction while focusing on the risk of exacerbation, health-care utilization, and medical expenses.

\section{Methods}

\section{Source of data}

In 1998, South Korea implemented a unique, compulsory, health insurance system for its population, and the corresponding National Health Insurance (NHI) database provides nationwide data with regard to illness and health-care utilization patterns. ${ }^{10}$ The Korean National Health and Nutrition Examination Survey (KNHANES) is conducted annually. In this study, we utilized KNHANES database records from 2007 to 2012 and merged with the NHI database for the same period. The KNHANES and NHI data of patients with COPD were linked by the Korean Centres for Disease Control and the Health Insurance Review and Assessment Service.

This study was exempted from the informed consent requirement because of its retrospective nature and was approved by the Institutional Review Board Committee of Kyung Hee University Hospital (IRB No. KHUH 2017-05-058).

\section{Definitions of COPD and BMI category}

COPD was defined as a spirometric airflow limitation (forced expiratory volume in $1 \mathrm{~s}\left[\mathrm{FEV}_{1}\right]$ /forced vital capacity $[\mathrm{FVC}]<0.70$ ) and only patients with COPD who met the following inclusion criteria were included: 1 ) age $\geq 40$ years, and 2) $\mathrm{FEV}_{1} \geq 50 \%$.

In Caucasians, obesity is defined as a BMI $\geq 30 \mathrm{~kg} / \mathrm{m}^{2}$; however, the World Health Organization (WHO) has proposed a cutoff of 25.0 for Asian populations, and this criterion is recommended by the Korean Society for the Study of Obesity. ${ }^{11,12}$ We adopted this cutoff value in the present study and subdivided patients by BMI into four categories: underweight $\left(\mathrm{BMI}<18.5 \mathrm{~kg} / \mathrm{m}^{2}\right)$, normal range $\left(18.5-22.9 \mathrm{~kg} / \mathrm{m}^{2}\right)$, overweight $\left(23-24.9 \mathrm{~kg} / \mathrm{m}^{2}\right)$, and obese $\left(\geq 25 \mathrm{~kg} / \mathrm{m}^{2}\right)$.

\section{Clinical data measurements}

We utilized and merged the Korean NHI (2008-2012) and KNHANES (2007-2012) data records of patients with COPD to investigate the impact of BMI on the risk of exacerbation and health-care utilization. The researchers were blinded to the subjects' personally identifiable information.

The KNHANES provides researchers with a variety of clinical information parameters such as age, sex, spirometry result, and smoking status. Spirometry was conducted by an experienced technician and the result was checked by technicians who were working in tertiary affiliated hospitals. Comorbid conditions were identified by searching for the International Classification of Disease, Tenth Revision (ICD-10) codes in the Health Insurance Review and Assessment (HIRA) Service database. Moreover, we analyzed health-care utilization and expenses extracted from the NHI database. We set 2007 as the baseline and used data from that year to assess the previous exacerbation history, whereas the medical expenses analysis targeted data from 2008. A moderate exacerbation was defined as an outpatient clinic visit for worsening respiratory symptoms and the prescription of antibiotics and/or systemic steroids, whereas a severe exacerbation was defined as an exacerbation necessitating hospitalization or an emergency department visit. In addition to all-cause health-care utilization and medical expenses, we evaluated COPD-related utilization and expenses. Data with regard to inpatient and outpatient services and the ICD-10 code of COPD (J43.x-J44.x) with prescription of COPDrelated medication were used.

All expenses are presented in US dollars (USD) with an exchange rate of 1 USD to 1,140 Korean won (May 2017 exchange rate).

\section{Statistical analysis}

Differences between the four BMI-stratified groups were assessed using the chi-square test for categorical variables and an analysis of variance for continuous variables. Because patients with COPD included in this study were detected by screening spirometry and usually had mild respiratory symptoms and relatively mild airflow limitation, exacerbation-related hospital visits were expected to be infrequent. Therefore, the incidence of exacerbation was analyzed using a negative binomial regression analysis model. 
The multivariable analyses were adjusted for covariates such as age, sex, $\mathrm{FEV}_{1}$, and smoking pack-year. Then, we conducted subgroup analyses according to the percent predicted $\mathrm{FEV}_{1}$ : $\mathrm{FEV}_{1} \geq 80 \%$, and $\mathrm{FEV}_{1} \geq 50$ but $<80 \%$ predicted. The 5 -year cumulative health-care utilization and medical expenses were expressed in terms of person-years and USD, respectively.

All analyses were two-sided and conducted at a significance level of 0.05 unless otherwise noted. All analyses were undertaken using SAS software, version 9.2 (SAS Institute Inc., Cary, NC, USA).

\section{Results}

\section{Characteristics of patients}

Among the 43,864 subjects who participated in KNHANES during the 6-year period, 1,320 were identified as COPD patients with mild to moderate airflow obstruction (Figure 1). Table 1 presents the demographic and clinical characteristics stratified by BMI category. Overall, $95.6 \%$ of patients were male, and $26.8 \%$ and $27.8 \%$ were overweight and obese, respectively. Younger age correlated significantly with an increased BMI, whereas the smoking rates were similar across BMI categories. Compared with a normal BMI, hypertension was more prevalent in the underweight and overweight/obesity groups, and osteoporosis was less prevalent in the obese group. The prevalence of other comorbidities was similar among the groups.

The groups did not differ with regard to a previous exacerbation history in the past year or initial treatment (including inhaler prescription). The EuroQol-5 Dimensions questionnaire (EQ-5D) scores were significantly lower in underweight patients, but did not differ among higher BMI groups. Furthermore, the underweight group had a low lung volume and more severe airflow limitation, whereas no significant trend was observed with increasing BMI (Table 2).

\section{Risk of exacerbation across the BMI categories}

Compared with the normal BMI group, the risk of moderate to severe exacerbation during 2008-2012 was significantly lower in the obese group (incidence rate ratio [IRR] 0.88 ; 95\% CI 0.77-0.99; $P$-value, 0.04). However, after adjusting for the covariates of age, sex, percent predicted $\mathrm{FEV}_{1}$, and/ or smoking pack-years, an increase in BMI did not correlate with a significant reduction in the exacerbation incidence (Table 3 ). In a subgroup analysis according to the percent predicted $\mathrm{FEV}_{1}-\mathrm{FEV}_{1} \geq 80 \%$, and $\mathrm{FEV}_{1} \geq 50$ but $<80 \%$ predicted - an increasing BMI was similarly not found to correlate significantly with a reduced incidence of exacerbation in either the adjusted or unadjusted models (Table S1).

\section{Health-care utilization and cost}

COPD-related events (person-year) and medical expenses (USD) are presented in Table 4. The underweight group experienced more frequent hospitalization, outpatient visits, and pharmacy utilization as well as medical expenses, whereas these parameters did not differ markedly among the three higher-weight groups (Figure S1). Notably, the obese group exhibited trends toward the lowest health-care utilization rate and medical expenses, except for pharmacy costs.

Table 5 presents the IRRs of 5-year COPD-related healthcare utilization. After adjusting for previously mentioned covariates, hospitalization was highest in the underweight group, although the overweight group exhibited an increased risk of hospitalization (adjusted IRRs: 7.12, 1.00, 1.26, and 1.02 for underweight, normal, overweight, and obese groups, respectively; $P=0.01$ ). The IRRs for hospitalization did not differ significantly between the groups divided by the percent predicted $\mathrm{FEV}_{1}$ (Table S2).

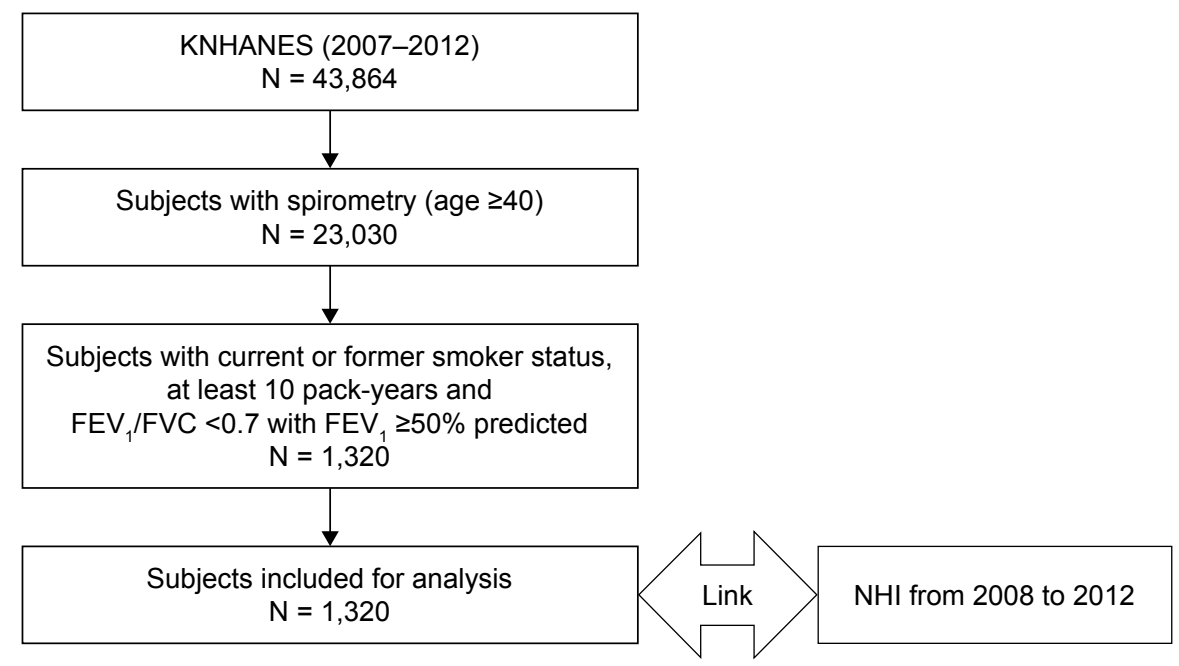

Figure I Flow diagram of the study participants. 
Table I Comparison of demographic and clinical characteristics among patients with chronic obstructive pulmonary disease (COPD) stratified by body mass index (BMI)*

\begin{tabular}{|c|c|c|c|c|c|}
\hline & \multicolumn{4}{|c|}{ BMI $\left(\mathrm{kg} / \mathrm{m}^{2}\right)$} & \multirow[t]{2}{*}{$P$-value } \\
\hline & $<\mathbf{I 8 . 5}$ & $18.5-22.9$ & $23-24.9$ & $\geq \mathbf{2 5}$ & \\
\hline Subjects & $37(2.8)$ & $562(42.6)$ & $354(26.8)$ & $367(27.8)$ & \\
\hline Age, years & $70.5 \pm 8.3$ & $65.5 \pm 9.2$ & $64.5 \pm 9.5$ & $62.4 \pm 9.6$ & $<0.01$ \\
\hline Sex, male (\%) & $33(89.2)$ & $529(95.9)$ & $344(97.2)$ & $356(97.0)$ & 0.08 \\
\hline BMI $\left(\mathrm{kg} / \mathrm{m}^{2}\right)$ & $17.5 \pm 0.8$ & $21.4 \pm 1.1$ & $23.9 \pm 0.6$ & $26.8 \pm 1.5$ & $<0.01$ \\
\hline Smoking, pack-year & $33.5 \pm 15.6$ & $35.3 \pm 21.0$ & $35.1 \pm 21.4$ & $35.6 \pm 20.9$ & 0.94 \\
\hline \multicolumn{6}{|l|}{ Comorbid condition } \\
\hline DM & II (29.7) & $205(36.5)$ & $133(37.6)$ & I $48(40.3)$ & 0.49 \\
\hline HTN & $22(59.5)$ & $274(48.8)$ & $196(55.4)$ & $234(63.8)$ & $<0.01$ \\
\hline Ischemic heart disease & $5(13.5)$ & $49(8.7)$ & $39(11.0)$ & $39(10.6)$ & 0.55 \\
\hline Congestive heart failure & $3(8.1)$ & $29(5.2)$ & $13(3.7)$ & $16(4.4)$ & 0.54 \\
\hline Arthritis & $5(13.5)$ & $54(9.6)$ & $34(9.6)$ & $38(10.4)$ & 0.87 \\
\hline Osteoporosis & II (29.7) & $72(12.8)$ & $46(13.0)$ & $32(8.7)$ & $<0.01$ \\
\hline GERD & $19(51.4)$ & $293(52.1)$ & $201(56.8)$ & $187(5 \mid .0)$ & 0.41 \\
\hline History of PTB & $0(0)$ & $5(0.9)$ & $6(1.7)$ & $\mathrm{I}(0.3)$ & 0.22 \\
\hline Depression & $9(24.3)$ & $77(13.7)$ & $49(13.8)$ & $51(13.9)$ & 0.35 \\
\hline \multicolumn{6}{|c|}{ History of exacerbation in the past year } \\
\hline Moderate to severe & $28(75.7)$ & $400(7 \mid .2)$ & $250(70.6)$ & $263(71.7)$ & 0.93 \\
\hline Frequency n/year & $4.1 \pm 5.5$ & $3.4 \pm 4.6$ & $3.0 \pm 4.0$ & $3.4 \pm 4.4$ & 0.40 \\
\hline \multicolumn{6}{|l|}{ Initial treatment, n (\%) } \\
\hline ICS and LABA & I (2.7) & $17(3.0)$ & $7(2.0)$ & II (3.0) & 0.79 \\
\hline LAMA and/or LABA & I (2.7) & $4(0.7)$ & $3(0.9)$ & $0(0)$ & 0.15 \\
\hline SABA and/or SAMA & $\mathrm{I}(2.7)$ & $23(4.1)$ & $14(4.0)$ & $17(4.6)$ & 0.93 \\
\hline
\end{tabular}

Note: *Data are presented as number $(\%)$ or mean \pm SD.

Abbreviations: BMI, body mass index; DM, diabetes mellitus; GERD, gastroesophageal reflux disease; HTN, hypertension; ICS, inhaled corticosteroid; LABA, longacting beta ${ }_{2}$ receptor agonist; LAMA, long-acting muscarinic receptor agonist; PTB, pulmonary tuberculosis; SABA, short-acting beta ${ }_{2}$ receptor agonist; SAMA, short-acting muscarinic receptor agonist.

\section{Discussion}

To our knowledge, this is the first study to assess the relationship of BMI with the risk of exacerbation and health-care utilization among patients - and, particularly, Asian patients - with
COPD with mild to moderate airflow obstruction. We found that underweight patients experienced more frequent clinic visits and hospitalization, whereas increase in BMI did not correlate significantly with increased COPD-related

Table 2 Comparison of the quality of life, laboratory findings, and pulmonary function among patients with chronic obstructive pulmonary disease (COPD)*

\begin{tabular}{|c|c|c|c|c|c|}
\hline & \multicolumn{4}{|l|}{ BMI $\left(\mathbf{k g} / \mathrm{m}^{2}\right)$} & \multirow[t]{2}{*}{$P$-value } \\
\hline & $<\mathbf{1 8 . 5}$ & $18.5-22.9$ & $23-24.9$ & $\geq 25$ & \\
\hline Subjects & $37(2.8)$ & $562(42.6)$ & $354(26.8)$ & $367(27.8)$ & \\
\hline \multicolumn{6}{|l|}{ Index of quality of life } \\
\hline EQ-5D & $0.86 \pm 0.18$ & $0.92 \pm 0.12$ & $0.93 \pm 0.11$ & $0.93 \pm 0.13$ & $<0.01$ \\
\hline \multicolumn{6}{|l|}{ Laboratory test } \\
\hline Total serum cholesterol, mg/dL & $167.3 \pm 40.5$ & $|87.1 \pm 36|$. & $187.6 \pm 36.9$ & $|89.8 \pm 35|$. & $<0.01$ \\
\hline $\mathrm{TG}, \mathrm{mg} / \mathrm{dL}$ & $126.5 \pm 116.3$ & $147.4 \pm 120.9$ & $167.2 \pm 102.9$ & $191.2 \pm 181.9$ & $<0.01$ \\
\hline LDL cholesterol, mg/dL & $109.5 \pm 23.4$ & $111.4 \pm 36.5$ & $109.8 \pm 38.6$ & $113.6 \pm 32.0$ & 0.93 \\
\hline HDL cholesterol, mg/dL & $49.4 \pm 12.2$ & $46.8 \pm 11.4$ & $44.4 \pm 11.0$ & $42.6 \pm 9.5$ & $<0.01$ \\
\hline \multicolumn{6}{|l|}{ Lung function } \\
\hline FVC, L & $3.4 \pm 0.7$ & $3.9 \pm 0.7$ & $4.0 \pm 0.8$ & $3.9 \pm 0.7$ & $<0.01$ \\
\hline FVC, \% predicted & $88.9 \pm 15.0$ & $92.5 \pm 12.7$ & $91.6 \pm 13.0$ & $87.4 \pm 12.6$ & $<0.01$ \\
\hline $\mathrm{FEV}_{1}, \mathrm{~L}$ & $2.1 \pm 0.5$ & $2.4 \pm 0.6$ & $2.5 \pm 0.6$ & $2.5 \pm 0.5$ & $<0.01$ \\
\hline $\mathrm{FEV}_{1}, \%$ predicted & $76.0 \pm 14.8$ & $78.7 \pm 12.9$ & $79.6 \pm 13.6$ & $77.9 \pm 12.0$ & 0.18 \\
\hline $\mathrm{FEV}_{1} / \mathrm{FVC}$ & $0.62 \pm 0.07$ & $0.63 \pm 0.06$ & $0.63 \pm 0.06$ & $0.65 \pm 0.05$ & $<0.01$ \\
\hline
\end{tabular}

Note: *Data are presented as number $(\%)$ or mean \pm SD.

Abbreviations: EQ-5D, EuroQol-5 Dimensions questionnaire; FEV , forced expiratory volume in I s; FVC, forced vital capacity; HDL, high-density lipoprotein; LDL, lowdensity lipoprotein; TG, triglyceride; BMI, body mass index. 
Table 3 Incidence of moderate to severe exacerbation during a 5-year period

\begin{tabular}{|c|c|c|c|c|c|c|c|c|c|}
\hline \multicolumn{10}{|c|}{ Incidence rate of moderate to severe exacerbation } \\
\hline BMI $\left(\mathrm{kg} / \mathrm{m}^{2}\right)$ & Crude IRR & $95 \% \mathrm{Cl}$ & $P$-value & Adjusted IRR ${ }^{\mathbf{a}}$ & $95 \% \mathrm{Cl}$ & $P$-value & Adjusted IRR & $95 \% \mathrm{Cl}$ & $P$-value \\
\hline$<18.5$ & 1.10 & $0.80-1.5 \mid$ & 0.57 & 0.94 & $0.69-1.29$ & 0.72 & 0.95 & $0.70-1.30$ & 0.75 \\
\hline $18.5-22.9$ & Reference & & & & & & & & \\
\hline $23-24.9$ & 0.94 & $0.82-1.06$ & 0.32 & 0.96 & $0.85-1.09$ & 0.52 & 0.96 & $0.85-1.09$ & 0.53 \\
\hline$\geq 25$ & 0.88 & $0.77-0.99$ & 0.04 & 0.97 & $0.86-1.10$ & 0.68 & 0.98 & $0.86-1.11$ & 0.70 \\
\hline
\end{tabular}

Notes: aAdjusted by age, sex, and FEV, (\%). ${ }^{b}$ Adjusted by age, sex, smoking pack-year and FEV $(\%)$.

Abbreviations: IRR, incidence rate ratio; BMI, body mass index.

health-care utilization; notably, we observed similar results for medical expenses. A low BMI is known to be associated with an increased risk of hospitalization in patients with COPD, ${ }^{6,713-15}$ and our findings confirm this relationship. In this study, we used the obesity definition for Asians, but the results were not significantly different even when using the Western BMI category proposed by WHO.

Although our results did not show a significant association between obesity and a higher risk of exacerbation or increased health-care utilization, several reports have described the harmful effects of obesity on COPD outcomes, including respiratory-specific quality of life (QOL), exercise capacity, and dyspnea severity. ${ }^{16,17}$ Similarly, Lambert et al ${ }^{18}$ recently reported the negative effects of obesity on outcomes related to moderate to severe COPD, including QOL, dyspnea, exercise tolerance, and severe exacerbation. More recently, patients with COPD who had undergone bariatric surgery experienced fewer emergency department visits and hospitalizations for COPD exacerbation. ${ }^{19}$

On the other hand, studies of asymptomatic COPD patients who had mild to moderate airflow obstruction are rare, as the affected patients generally do not experience sufficiently severe symptoms that would induce a voluntary hospital visit. Therefore, clinical practices find it extremely difficult to enroll those patients. However, we benefited from the use of the KNHANES to identify these patients. The patients diagnosed with COPD in the KNHANES database were asymptomatic. Their EQ-5D scores were almost normal, and almost none had received a previous COPD diagnosis or treatment. ${ }^{20}$ Most patients did not know their COPD status and were identified incidentally via spirometry screening. An extremely low frequency of inhaler prescriptions and low EQ-5D scores indicate that the population in this study truly comprised patients with asymptomatic COPD. Furthermore, it is difficult to follow up these patients. Despite the incidental diagnosis of COPD, patients who are largely asymptomatic have little motivation to participate in regular follow-ups. Similarly, routine hospital visits are very rare. Fortunately, however, we were able to connect patient information to the HIRA database. This allowed us to trace all health-care utilization and expense data without omission.

Few studies have investigated the characteristics and courses of patients with asymptomatic COPD who are expected to progress to symptomatic COPD over time. ${ }^{21}$

Table 4 Cumulative chronic obstructive pulmonary disease (COPD)-related health-care utilization and medical expenses ${ }^{\#}$ during a 5 -year period*

\begin{tabular}{|c|c|c|c|c|c|}
\hline & \multicolumn{4}{|l|}{ BMI $\left(\mathbf{k g} / \mathrm{m}^{2}\right)$} & \multirow[t]{2}{*}{$P$-value } \\
\hline & $<\mathbf{1 8 . 5}$ & $18.5-22.9$ & 23-24.9 & $\geq \mathbf{2 5}$ & \\
\hline Subjects & $37(2.8)$ & $562(42.6)$ & $354(26.8)$ & $367(27.8)$ & \\
\hline \multicolumn{6}{|c|}{ COPD-related health-care utilization and medical expenses } \\
\hline \multicolumn{6}{|l|}{ Hospitalization } \\
\hline Number per person-year & $4.7 \pm 9.6$ & $\mathrm{I} . \mathrm{I} \pm 5.4$ & $1.7 \pm 6.8$ & $0.8 \pm 3.9$ & $<0.01$ \\
\hline Cost per person-year & $846.5 \pm 1,933.5$ & $248.6 \pm 1,575.5$ & $283.2 \pm 1,144.0$ & $183.0 \pm 956.5$ & 0.04 \\
\hline \multicolumn{6}{|l|}{ Outpatient clinic visits } \\
\hline Number per person-year & $3.6 \pm 5.9$ & $3.0 \pm 3.7$ & $2.7 \pm 4.0$ & $2.3 \pm 2.9$ & 0.04 \\
\hline Cost per person-year & $61.9 \pm 100.0$ & $45.3 \pm 84.5$ & $53.3 \pm 178.0$ & $37.7 \pm 62.8$ & 0.24 \\
\hline \multicolumn{6}{|l|}{ Pharmacy use } \\
\hline Number per person-year & $3.5 \pm 5.9$ & $2.9 \pm 3.6$ & $2.6 \pm 3.9$ & $2.3 \pm 2.8$ & 0.04 \\
\hline Cost per person-year & $22.7 \pm 47.0$ & $19.7 \pm 41.9$ & $17.5 \pm 27.5$ & $19.9 \pm 41.7$ & 0.75 \\
\hline
\end{tabular}

Notes: \#All costs are presented in US dollars (USD) with an exchange rate of I USD equal to I, I40 Korean won (exchange rate on May, 20I7). *Data are presented as number $(\%)$ or mean \pm SD.

Abbreviation: BMI, body mass index. 
Table 5 Risk of chronic obstructive pulmonary disease (COPD)-related health-care utilization during a 5-year period

\begin{tabular}{|c|c|c|c|c|c|c|c|c|c|}
\hline \multirow{2}{*}{$\begin{array}{l}\text { BMI } \\
\left(\mathrm{kg} / \mathrm{m}^{2}\right) \\
\text { group }\end{array}$} & \multicolumn{3}{|c|}{ Crude IRR (95\% CI) } & \multicolumn{3}{|c|}{ Adjusted IRR ${ }^{a}(95 \% \mathrm{Cl})$} & \multicolumn{3}{|c|}{ Adjusted IRR ${ }^{\mathrm{b}}(95 \% \mathrm{Cl})$} \\
\hline & Hospitalization & $\begin{array}{l}\text { Outpatient } \\
\text { clinic visits }\end{array}$ & $\begin{array}{l}\text { Pharmacy } \\
\text { use }\end{array}$ & Hospitalization & $\begin{array}{l}\text { Outpatient } \\
\text { clinic visits }\end{array}$ & $\begin{array}{l}\text { Pharmacy } \\
\text { use }\end{array}$ & Hospitalization & $\begin{array}{l}\text { Outpatient } \\
\text { clinic visits }\end{array}$ & $\begin{array}{l}\text { Pharmacy } \\
\text { use }\end{array}$ \\
\hline$<18.5$ & $\begin{array}{l}4.65 \\
(0.46-47.03)\end{array}$ & $\begin{array}{l}1.22 \\
(0.73-1.98)\end{array}$ & $\begin{array}{l}1.19 \\
(0.72-1.96)\end{array}$ & $\begin{array}{l}4.93 \\
(0.52-46.38)\end{array}$ & $\begin{array}{l}0.83 \\
(0.52-1.34)\end{array}$ & $\begin{array}{l}0.82 \\
(0.5 I-\mid .33)\end{array}$ & $\begin{array}{l}7.12 \\
(0.77-66.02)\end{array}$ & $\begin{array}{l}0.82 \\
(0.51-1.32)\end{array}$ & $\begin{array}{l}0.90 \\
(0.82-0.99)\end{array}$ \\
\hline $18.5-22.9$ & Reference & & & & & & & & \\
\hline $23-24.9$ & $\begin{array}{l}1.17 \\
(0.46-2.96)\end{array}$ & $\begin{array}{l}0.89 \\
(0.73-1.09)\end{array}$ & $\begin{array}{l}0.87 \\
(0.7 I-1.06)\end{array}$ & $\begin{array}{l}1.02 \\
(0.42-2.50)\end{array}$ & $\begin{array}{l}0.95 \\
(0.78-I .15)\end{array}$ & $\begin{array}{l}0.93 \\
(0.76-I .12)\end{array}$ & $\begin{array}{l}1.26 \\
(0.50-3.16)\end{array}$ & $\begin{array}{l}0.95 \\
(0.79-I .15)\end{array}$ & $\begin{array}{l}0.92 \\
(0.88-0.96)\end{array}$ \\
\hline$\geq 25$ & $\begin{array}{l}0.70 \\
(0.28-1.75)\end{array}$ & $\begin{array}{l}0.73 \\
(0.60-0.89)\end{array}$ & $\begin{array}{l}0.73 \\
(0.60-0.89)\end{array}$ & $\begin{array}{l}0.79 \\
(0.33-1.94)\end{array}$ & $\begin{array}{l}0.87 \\
(0.72-1.05)\end{array}$ & $\begin{array}{l}0.87 \\
(0.72-1.05)\end{array}$ & $\begin{array}{l}1.02 \\
(0.4 \mid-2.52)\end{array}$ & $\begin{array}{l}0.87 \\
(0.72-1.06)\end{array}$ & $\begin{array}{l}0.82 \\
(0.79-0.86)\end{array}$ \\
\hline$P$ for trend & 0.25 & 0.01 & 0.01 & 0.25 & 0.50 & 0.48 & 0.01 & 0.52 & $<0.01$ \\
\hline
\end{tabular}

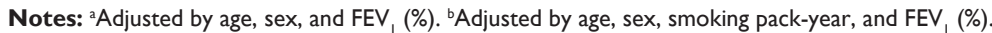

Abbreviations: IRR, incidence rate ratio; BMI, body mass index.

In a general population, obesity can induce systemic comorbidities, such as diabetes mellitus and cardiovascular disease, and is known to correlate with increased mortality relative to that associated with normal weight. ${ }^{22}$ Paradoxically, increased weight and mild obesity have been reported to yield survival benefits among patients with COPD.$^{6,723} \mathrm{Cao}$ et al ${ }^{23}$ reported a meta-analysis of 22 studies with 21,150 individuals to evaluate the association between BMI and mortality in COPD. Relative to normal weight, decreased weight was associated with increased mortality (relative risk [RR] 1.34; 95\% CI 1.01-1.78), whereas increased weight (RR 0.47; 95\% CI $0.33-0.68$ ) and obesity (RR 0.59 ; $95 \%$ CI $0.38-0.91$ ) were associated with reduced mortality. Moreover, our results suggest a protective effect of increasing BMI against poor outcomes among COPD patients with mild to moderate airflow obstruction. The exact pathophysiology underlying this protective effect is poorly understood, despite increasing interest. However, the possible mechanisms underlying the positive effect of decreased weight on the unfavorable outcomes of COPD include sarcopenia and muscle weakness, ${ }^{24,25}$ inactivity, ${ }^{26}$ and systemic inflammation. ${ }^{26,27}$

In our study, obese patients tended to use medical care less frequently and had fewer medical expenses, compared with normal-weight patients. This relationship was more apparent among patients with relatively more severe airflow limitations. Our results are consistent with a previous study on the natural course of asymptomatic COPD patients with mild to moderate airflow obstruction, which suggested that patients with risk factors (eg, old age, lower BMI, reduced function, low EQ-5D scores) should be diagnosed and treated before disease progression. ${ }^{28}$

In practice, it is difficult to assess the prevalence of asymptomatic COPD - either alone or according to BMI - as these patients are not expected to visit hospitals frequently and clinicians might not conduct a spirometry screening for mild respiratory symptoms. Our study was made possible by access to large, well-designed national databases that encompass both demographic and functional test results. Furthermore, there was no missing data, and the NHI database allowed us to assess medical expenses. One interesting and valuable strength of this nationwide study is the potential for a long-term follow-up evaluation of the same group of patients. We could therefore assess the impact of BMI on progression to overt, symptomatic COPD from mild, asymptomatic COPD.

It remains unclear whether treating asymptomatic COPD could delay disease progression and change the outcome. However, the pathogenesis and continuum of disease progression suggest that early treatment might influence the course of disease. Despite evidence suggesting that obese patients with COPD have a better prognosis, we do not recommend being obese, as physical exercise and active rehabilitation are essential to improving exercise capacity, and proper nutritional support might play an important role. The finding that physically inactive and extremely obese patients with COPD had worse outcomes was very clear.

This may be the first study assessing the impact of BMI on the outcome of asymptomatic COPD patients with mild to moderate airflow obstruction, but several limitations must be considered. First, although we used various nationwide data, this was a retrospective study. Second, the KNHANES dataset does not include COPD-specific QOL assessment tools. Third, to clarify COPD diagnosis, COPD was defined by spirometry and smoking status. This might have resulted in male predominance of the sample population. Moreover, we did not consider biomass exposure-related airflow limitations because they are not easily quantified and might lead to a risk of over-diagnosis of COPD as well. Fourth, COPD was not defined by a fixed, irreversible airflow limitation because post-bronchodilator (BD) spirometric values were 
not available. However, a previous large cohort study found that pre- and post-BD results were interchangeable. ${ }^{24,25}$ Moreover, the definition of exacerbation we used has not been validated. However, the same definition of exacerbation was applied in other studies. ${ }^{29,30}$ Lastly, all study participants were Korean; therefore, our results may not be generalizable to other populations. However, previous studies on BMI and COPD were mostly conducted in Western populations. Accordingly, Asia-specific data are scarce. Therefore, this study provides valuable information on the role of BMI in Asian patients with COPD.

\section{Conclusion}

In summary, we found a negative influence of decreased weight on the clinical outcomes of COPD patients with mild to moderate airflow obstruction, whereas an increasing BMI (relative to normal BMI) had no significant negative effect on prognosis.

\section{Disclosure}

The authors report no conflicts of interest in this work.

\section{References}

1. Mannino DM, Braman S. The epidemiology and economics of chronic obstructive pulmonary disease. Proc Am Thorac Soc. 2007;4(7): 502-506.

2. van Manen JG, Bindels PJ, IJzermans CJ, van der Zee JS, Bottema BJ, Schadé E. Prevalence of comorbidity in patients with a chronic airway obstruction and controls over the age of 40. J Clin Epidemiol. 2001; 54(3):287-293.

3. García-Rio F, Soriano JB, Miravitlles M, et al. Impact of obesity on the clinical profile of a population-based sample with chronic obstructive pulmonary disease. PLoS One. 2014;9(8):e105220.

4. Cecere LM, Littman AJ, Slatore CG, et al. Obesity and COPD: associated symptoms, health-related quality of life, and medication use. COPD. 2011;8(4):275-284.

5. Schaberg T, Reichert B, Schülin T, Lode H, Mauch H. Rapid drug susceptibility testing of Mycobacterium tuberculosis using conventional solid media. Eur Respir J. 1995;8(10):1688-1693.

6. Landbo C, Prescott E, Lange P, Vestbo J, Almdal TP. Prognostic value of nutritional status in chronic obstructive pulmonary disease. Am J Respir Crit Care Med. 1999;160(6):1856-1861.

7. Guo Y, Zhang T, Wang Z, et al. Body mass index and mortality in chronic obstructive pulmonary disease: a dose-response meta-analysis. Medicine (Baltimore). 2016;95(28):e4225.

8. Shin HY, Kang HT. Recent trends in the prevalence of underweight, overweight, and obesity in Korean adults: the Korean National Health and Nutrition Examination Survey from 1998 to 2014. J Epidemiol.2017; 27(9):413-419.

9. Jo YS, Choi SM, Lee J, et al. The relationship between chronic obstructive pulmonary disease and comorbidities: a cross-sectional study using data from KNHANES 2010-2012. Respir Med. 2015;109(1):96-104.

10. Lee YH, Yoon SJ, Kim EJ, Kim YA, Seo HY, Oh IH. Economic burden of asthma in Korea. Allergy Asthma Proc. 2011;32(6):35-40.
11. World Health Organization. The Asia-Pacific Perspective: Redefining Obesity and its Treatment. Sydney: Health Communications Australia; 2000.

12. Kim MK, Lee WY, Kang JH, et al; Committee of Clinical Practice Guidelines; Korean Society for the Study of Obesity. 2014 clinical practice guidelines for overweight and obesity in Korea. Endocrinol Metab (Seoul). 2014;29(4):405-409.

13. Çolak Y, Afzal S, Lange P, Nordestgaard BG. High body mass index and risk of exacerbations and pneumonias in individuals with chronic obstructive pulmonary disease: observational and genetic risk estimates from the Copenhagen General Population Study. Int J Epidemiol. 2016; 45(5):1551-1559.

14. Ong KC, Earnest A, Lu SJ. A multidimensional grading system (BODE index) as predictor of hospitalization for COPD. Chest. 2005;128(6): 3810-3816.

15. Marin JM, Carrizo SJ, Casanova C, et al. Prediction of risk of COPD exacerbations by the BODE index. Respir Med. 2009;103(3):373-378.

16. Launois C, Barbe C, Bertin E, et al. The modified Medical Research Council scale for the assessment of dyspnea in daily living in obesity: a pilot study. BMC Pulm Med. 2012;12:61.

17. Rodríguez DA, Garcia-Aymerich J, Valera JL, et al; PAC-COPD Study Group. Determinants of exercise capacity in obese and non-obese COPD patients. Respir Med. 2014;108(5):745-751.

18. Lambert AA, Putcha N, Drummond MB, et al; COPDGene Investigators. Obesity is associated with increased morbidity in moderate to severe COPD. Chest. 2017;151(1):68-77.

19. Goto T, Tsugawa Y, Faridi MK, Camargo CA Jr, Hasegawa K. Reduced risk of acute exacerbation of COPD after bariatric surgery: a selfcontrolled case series study. Chest. 2018;153(3):611-617.

20. Yoo KH, Kim YS, Sheen SS, et al. Prevalence of chronic obstructive pulmonary disease in Korea: the fourth Korean National Health and Nutrition Examination Survey, 2008. Respirology. 2011;16(4):659-665.

21. Decramer M, Cooper CB. Treatment of COPD: the sooner the better? Thorax. 2010;65(9):837-841.

22. Jee SH, Sull JW, Park J, et al. Body-mass index and mortality in Korean men and women. N Engl J Med. 2006;355(8):779-787.

23. Cao C, Wang R, Wang J, Bunjhoo H, Xu Y, Xiong W. Body mass index and mortality in chronic obstructive pulmonary disease: a meta-analysis. PLoS One. 2012;7(8):e43892.

24. Vestbo J, Prescott E, Almdal T, et al. Body mass, fat-free body mass, and prognosis in patients with chronic obstructive pulmonary disease from a random population sample: findings from the Copenhagen City Heart Study. Am J Respir Crit Care Med. 2006;173(1):79-83.

25. Ischaki E, Papatheodorou G, Gaki E, Papa I, Koulouris N, Loukides S. Body mass and fat-free mass indices in COPD: relation with variables expressing disease severity. Chest. 2007;132(1):164-169.

26. Franssen FM, O'Donnell DE, Goossens GH, Blaak EE, Schols AM. Obesity and the lung: 5. Obesity and COPD. Thorax. 2008;63(12): 1110-1117.

27. Tomoda $\mathrm{K}$, Yoshikawa M, Itoh $\mathrm{T}$, et al. Elevated circulating plasma adiponectin in underweight patients with COPD. Chest. 2007;132(1): $135-140$.

28. Rhee CK, Kim K, Yoon HK, et al. Natural course of early COPD. Int J Chron Obstruct Pulmon Dis. 2017;12:663-668.

29. Vestbo J, Papi A, Corradi M, et al. Single inhaler extrafine triple therapy versus long-acting muscarinic antagonist therapy for chronic obstructive pulmonary disease (TRINITY): a double-blind, parallel group, randomised controlled trial. Lancet. 2017;389(10082):1919-1929.

30. Lipson DA, Barnacle H, Birk R, et al. FULFIL Trial: once-daily triple therapy for patients with chronic obstructive pulmonary disease. Am J Respir Crit Care Med. 2017;196(4):438-446. 


\section{Supplementary materials}

Table SI Subgroup analysis of the risk of exacerbation according to the severity of airflow limitation

\begin{tabular}{|c|c|c|c|c|c|}
\hline \multirow[t]{2}{*}{ IRR (95\% CI) } & \multicolumn{4}{|c|}{ BMI $\left(\mathrm{kg} / \mathrm{m}^{2}\right)$ group } & \multirow[t]{2}{*}{$P$-value } \\
\hline & $<\mathbf{I 8 . 5}$ & $18.5-22.9$ & $23-24.9$ & $\geq \mathbf{2 5}$ & \\
\hline \multicolumn{6}{|c|}{$\mathrm{FEV}_{1} \geq 80 \%$ predicted } \\
\hline Crude IRR & $1.01(0.6 \mathrm{I}-\mathrm{I} .67)$ & Reference & $0.90(0.74-1.08)$ & $0.88(0.72-1.07)$ & 0.51 \\
\hline Adjusted IRR ${ }^{\mathrm{a}}$ & $0.88(0.54-1.45)$ & & $0.89(0.75-1.07)$ & $0.98(0.8 I-1.19)$ & 0.65 \\
\hline Adjusted IRR ${ }^{\mathrm{b}}$ & $0.89(0.54-1.46)$ & & $0.90(0.75-1.07)$ & $0.98(0.81-1.20)$ & 0.66 \\
\hline \multicolumn{6}{|c|}{$50 \% \leq \mathrm{FEV},<80 \%$ predicted } \\
\hline Crude IRR & $1.16(0.77-1.74)$ & Reference & $0.98(0.82-1.17)$ & $0.88(0.74-1.04)$ & 0.33 \\
\hline Adjusted IRR ${ }^{a}$ & $0.99(0.67-1.47)$ & & $1.02(0.86-1.22)$ & $0.99(0.84-1.16)$ & 0.98 \\
\hline Adjusted IRR ${ }^{b}$ & $0.99(0.67-1.47)$ & & $1.02(0.86-1.21)$ & $0.98(0.84-1.16)$ & 0.98 \\
\hline
\end{tabular}

Notes: ${ }^{2}$ Adjusted by age, sex, and FEV,$(\%)$. ${ }^{b}$ Adjusted by age, sex, smoking pack-year, and $\mathrm{FEV}_{1}(\%)$.

Abbreviations: IRR, incidence rate ratio; $\mathrm{FEV}_{1}$, forced expiratory volume in I s; $\mathrm{BMI}$, body mass index.

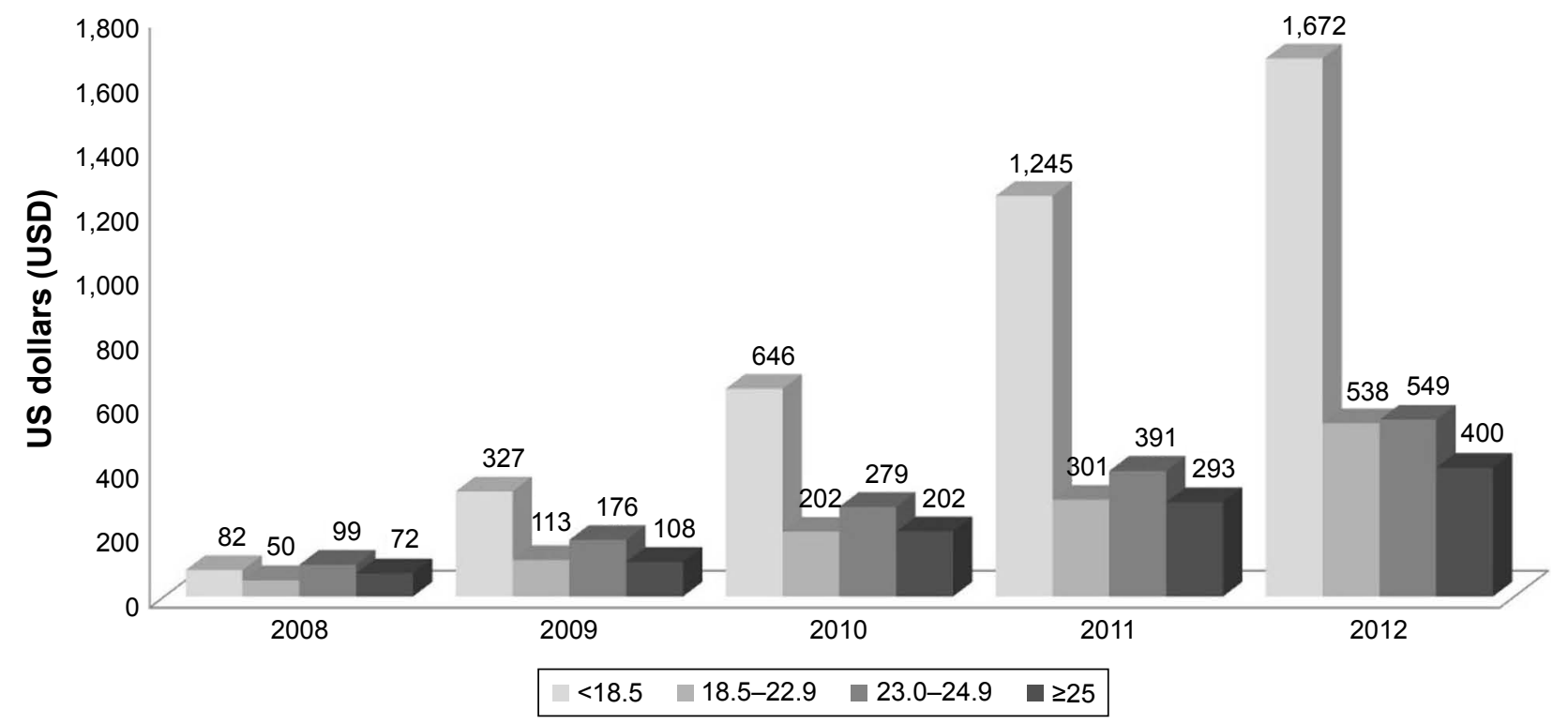

Figure SI Cumulative chronic obstructive pulmonary disease (COPD)-related medical costs per person-year stratified by body mass index (BMI). Note: Medical costs are presented in US dollars (USD) with an exchange rate of I USD equal to I, I40 Korean won (exchange rate on May, 20I7). 
Table S2 Subgroup analysis of the risk of chronic obstructive pulmonary disease (COPD)-related health-care utilization during a 5 -year period according to the forced expiratory volume in I $\mathrm{s}\left(\mathrm{FEV}_{1}\right)$

\begin{tabular}{|c|c|c|c|c|c|}
\hline \multirow[t]{2}{*}{ IRR (95\% CI) } & \multicolumn{4}{|l|}{ BMI $\left(\mathrm{kg} / \mathrm{m}^{2}\right)$} & \multirow[t]{2}{*}{$P$ for trend } \\
\hline & $<\mathbf{1 8 . 5}$ & $18.5-22.9$ & $23-24.9$ & $\geq 25$ & \\
\hline \multicolumn{6}{|l|}{$\mathrm{FEV}_{1} \geq 80 \%$ predicted } \\
\hline \multicolumn{6}{|l|}{ Crude IRR } \\
\hline Hospitalization & $7.20(0.20-265.07)$ & Reference & $1.24(0.33-4.66)$ & $0.57(0.14-2.32)$ & 0.33 \\
\hline Outpatient clinic visits & $0.52(0.28-0.96)$ & & $1.04(0.85-1.26)$ & $0.89(0.72-1.10)$ & 0.11 \\
\hline Pharmacy use & $0.33(0.15-0.73)$ & & $1.04(0.79-1.37)$ & $0.90(0.67-1.19)$ & 0.08 \\
\hline \multicolumn{6}{|l|}{ Adjusted IRR ${ }^{a}$} \\
\hline Hospitalization & $10.04(0.29-348.56)$ & & $1.08(0.30-3.92)$ & $0.58(0.14-2.38)$ & 0.20 \\
\hline Outpatient clinic visits & $0.45(0.24-0.82)$ & & $1.05(0.87-1.27)$ & $0.97(0.79-1.19)$ & 0.05 \\
\hline Pharmacy use & $0.27(0.12-0.59)$ & & $1.05(0.80-1.36)$ & $1.00(0.76-1.33)$ & 0.03 \\
\hline \multicolumn{6}{|l|}{ Adjusted IRR ${ }^{\mathrm{b}}$} \\
\hline Hospitalization & $12.22(0.37-402.38)$ & & $1.25(0.34-4.58)$ & $0.61(0.15-2.40)$ & 0.15 \\
\hline Outpatient clinic visits & $0.45(0.24-0.82)$ & & $1.05(0.87-1.27)$ & $0.97(0.79-1.19)$ & 0.05 \\
\hline Pharmacy use & $0.28(0.20-0.38)$ & & $1.08(1.01-1.15)$ & $0.99(0.92-1.07)$ & $<0.01$ \\
\hline \multicolumn{6}{|c|}{$\mathbf{5 0} \% \leq$ FEV,$<\mathbf{8 0} \%$ predicted } \\
\hline \multicolumn{6}{|c|}{ Crude IRR } \\
\hline Hospitalization & $2.57(0.15-42.62)$ & Reference & $1.70(0.50-5.77)$ & $0.84(0.27-2.63)$ & 0.63 \\
\hline Outpatient clinic visits & $1.58(0.98-2.55)$ & & $0.86(0.70-1.07)$ & $0.73(0.59-0.89)$ & $<0.01$ \\
\hline Pharmacy use & $1.53(0.79-2.96)$ & & $0.78(0.59-1.04)$ & $0.64(0.49-0.84)$ & $<0.01$ \\
\hline \multicolumn{6}{|l|}{ Adjusted IRR ${ }^{a}$} \\
\hline Hospitalization & $2.68(0.18-40.95)$ & & $1.36(0.4 \mid-4.48)$ & $1.21(0.39-3.73)$ & 0.86 \\
\hline Outpatient clinic visits & $1.22(0.79-1.90)$ & & $0.89(0.72-1.09)$ & $0.86(0.7 I-1.05)$ & 0.25 \\
\hline Pharmacy use & $1.14(0.6 \mathrm{I}-2.14)$ & & $0.83(0.63-1.09)$ & $0.78(0.60-1.01)$ & 0.22 \\
\hline \multicolumn{6}{|l|}{ Adjusted IRR ${ }^{b}$} \\
\hline Hospitalization & $3.14(0.21-46.92)$ & & I.64 (0.49-5.54) & $\mathrm{I} .37(0.44-4.2 \mathrm{I})$ & 0.73 \\
\hline Outpatient clinic visits & $1.21(0.78-1.87)$ & & $0.86(0.70-1.05)$ & $0.85(0.70-1.03)$ & 0.16 \\
\hline Pharmacy use & $1.11(1.00-1.23)$ & & $0.79(0.75-0.84)$ & $0.73(0.69-0.78)$ & $<0.01$ \\
\hline
\end{tabular}

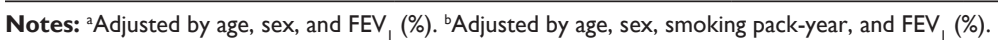

Abbreviations: IRR, incidence rate ratio; $\mathrm{BMI}$, body mass index; $\mathrm{FEV}_{1}$, forced expiratory volume in I s.

\section{Publish your work in this journal}

The International Journal of COPD is an international, peer-reviewed journal of therapeutics and pharmacology focusing on concise rapid reporting of clinical studies and reviews in COPD. Special focus is given to the pathophysiological processes underlying the disease, intervention programs, patient focused education, and self management protocols.

\section{Dovepress}

This journal is indexed on PubMed Central, MedLine and CAS. The manuscript management system is completely online and includes a very quick and fair peer-review system, which is all easy to use. Visit http://www.dovepress.com/testimonials.php to read real quotes from published authors. 